\title{
The Impact of Electronic Media Violence: Scientific Theory and Research
}

\author{
L. Rowell Huesmann, Ph.D.* \\ Institute for Social Research, The University of Michigan, Ann Arbor, Michigan \\ Manuscript received June 28, 2007; manuscript accepted September 19, 2007
}

\begin{abstract}
Since the early 1960s, research evidence has been accumulating that suggests that exposure to violence in television, movies, video games, cell phones, and on the Internet increases the risk of violent behavior on the viewer's part, just as growing up in an environment filled with real violence increases the risk of them behaving violently. In the current review this research evidence is critically assessed and the psychological theory that explains why exposure to violence has detrimental effects for both the short and long-term is elaborated. Finally the size of the "media violence effect" is compared with some other well-known threats to society to estimate how important a threat it should be considered. (C) 2007 Society for Adolescent Medicine. All rights reserved.
\end{abstract}

Keywords:

Youth violence; Media; Video games; Television

One of the notable changes in our social environment in the $20^{\text {th }}$ and $21^{\text {st }}$ centuries has been the saturation of our culture and daily lives by the mass media. In this new environment radio, television (TV), movies, videos, video games, cell phones, and computer networks have assumed central roles in our children's daily lives. For better or worse the mass media are having an enormous impact on our children's values, beliefs, and behaviors. Unfortunately, the consequences of one particular common element of the electronic mass media have a particularly detrimental effect on children's well being. Research evidence has accumulated over the past half-century that exposure to violence on television, movies, and, most recently, in video games increases the risk of violent behavior on the viewer's part, just as growing up in an environment filled with real violence increases the risk of violent behavior. Correspondingly, the recent increase in the use of mobile phones, text messaging, e-mail, and chat rooms by our youth have opened new venues for social interaction in which aggression can occur

\footnotetext{
*Address correspondence to: L. Rowell Huesmann, Ph.D., Amos N. Tversky Collegiate Professor of Communication Studies and Psychology, and Director, Research Center for Group Dynamics, Institute for Social Research, The University of Michigan, 426 Thompson Street, Ann Arbor, MI 48106.

E-mail address: huesmann@umich.edu
}

and youth can be victimized-new venues that break the old boundaries of family, neighborhood, and community that might have protected our youth to some extent in the past. These globe-spanning electronic communication media have not really introduced new psychological threats to our children; but they have made it much harder to protect youth from the threats, and have exposed many more of them to threats that only a few might have experienced before. It is now not just kids in bad neighborhoods or with "bad" friends who are likely to be exposed to bad things when they go out on the street. A "virtual" bad street is easily available to most youth now. However, our response should not be to panic and keep our children indoors because the "streets" out there are dangerous. The streets also provide wonderful experiences and help youth to become the kinds of adults we desire. Rather our response should be to understand the dangers on the streets, to help our children understand and avoid the dangers, to avoid exaggerating the dangers (which would destroy our credibility), and also to try to control exposure to the extent that we can.

\section{Background}

Different people may have quite different things in mind when they think of media violence. Similarly, among the 
public there may be little consensus on what constitutes aggressive and violent behavior. Most researchers, however, have clear conceptions of what they mean by media violence and aggressive behavior.

In general researchers define media violence as visual portrayals of acts of physical aggression by one human or human-like character against another. This definition has evolved as theories about the effects of media violence have evolved, and represents an attempt to describe the kind of violent media presentation that is most likely to teach the viewer to be more violent. Movies depicting violence of this type were frequent 75 years ago and are even more frequent today (e.g., M, The Maltese Falcon, Shane, Dirty Harry, Pulp Fiction, Natural Born Killers, Kill Bill). Violent TV programs became common shortly after TV became common in American homes about 55 years ago, and remain common today (e.g., Gunsmoke, Miami Vice, CSI, and 24). More recently, video games, Internet displays, and cell phone displays have become part of most children's growing-up, and violent displays on them have become common (e.g., Grand Theft Auto, Resident Evil, Warrior).

To most researchers, aggressive behavior refers to an act that is intended to injure or irritate another person. Lay persons may call assertive salesmen "aggressive," but researchers do not because there is no intent to harm. Aggression can be physical or nonphysical, and it includes many kinds of behavior that do not seem to fit the commonly understood meaning of "violence." Insults and spreading harmful rumors fit the definition. Of course the aggressive behaviors of greatest concern clearly involve physical aggression, ranging in severity from pushing or shoving, to fighting, to serious assaults and homicide. In this review the term violent behavior is used to describe these more serious forms of physical aggression that have a significant risk of seriously injuring the victim.

Violent or aggressive actions seldom result from a single cause; rather multiple factors converging over time contribute to such behavior. Accordingly the influence of the violent mass media is best viewed as one of the many potential factors that influence the risk for violence and aggression. No reputable researcher is suggesting that media violence is the sole cause of violent behavior. Furthermore a developmental perspective is essential for an adequate understanding of how media violence affects youthful conduct, and to formulate a coherent response to this problem. Most youth who are aggressive and engage in some forms of antisocial behavior do not go on to become violent teens and adults [1]. Still research has shown that a significant proportion of aggressive children are likely to grow up to be aggressive adults, and that seriously violent adolescents and adults often were highly aggressive and even violent as children [2]. The best single predictor of violent behavior in older adolescents, young adults, and even middle-aged adults is aggressive behavior when they were younger. Thus anything that promotes aggressive behavior in young children statistically is a risk factor for violent behavior in adults as well.

\section{Theoretical Explanations for Media Violence Effects}

To understand the empirical research implicating violence in electronic media as a threat to society, an understanding of why and how violent media cause aggression is vital. In fact psychological theories that explain why media violence is such a threat are now well established. Furthermore these theories also explain why the observation of violence in the real world - among family members, among peers, and within the community-also stimulates aggressive behavior in the observer.

Somewhat different processes seem to cause short-term effects of violent content and long-term effects of violent content, and that both of these processes are distinct from the time displacement effects that engagement in media may have on children. Time displacement effects refer to the role of the mass media (including video games) in displacing other activities in which the child might engage that might change the risk for certain kinds of behavior (e.g. replacing reading, athletics, etc.). This review focuses on the effects of violent media content; displacement effects will not be reviewed here, although they may well have important consequences.

\section{Short-term effects}

Most theorists would now agree that the short-term effects of exposure to media violence are mostly due to the following: 1) priming processes, 2) arousal processes, and 3 ) immediate mimicking of specific behaviors $[3,4]$.

Priming. Priming is the process through which spreading activation in the brain's neural network from the locus representing an external observed stimulus excites another brain node representing a cognition, emotion, or behavior. The external stimulus can be inherently linked to a cognition (e.g., the sight of a gun is inherently linked to the concept of aggression) [5], or the external stimulus can be something inherently neutral such as a particular ethnic group (e.g., African-American) that has become linked in the past to certain beliefs or behaviors (e.g., welfare). The primed concepts make behaviors linked to them more likely. When media violence primes aggressive concepts, aggression is more likely.

Arousal. To the extent that mass media presentations arouse the observer, aggressive behavior may also become more likely in the short run, for two possible reasons-excitation transfer [6] and general arousal [7]. First a subsequent stimulus that arouses an emotion (e.g., a provocation arousing anger) may be perceived as more severe than it is because some of the emotional response stimulated by the media presentation is miss-attributed to the provocation. For 
example, immediately after an exciting media presentation, such excitation transfer could cause more aggressive responses to provocation. Alternatively the increased general arousal stimulated by the media presentation may simply reach such a peak that inhibition of inappropriate responses is diminished, and dominant learned responses are displayed in social problem solving (e.g., direct instrumental aggression).

Mimicry. The third short-term process, imitation of specific behaviors, can be viewed as a special case of the more general long-term process of observational learning [8]. In recent years evidence has accumulated that human and primate young have an innate tendency to mimic whomever they observe [9]. Observation of specific social behaviors around them increases the likelihood of children behaving exactly that way. Specifically, as children observe violent behavior, they are prone to mimic it. The neurological process through which this happens is not completely understood, but it seems likely that "mirror neurons" that fire when either a behavior is observed or when the same behavior is acted out, play an important role $[4,10]$.

\section{Long-term effects}

Long-term content effects, on the other hand, seem to be due to 1) more lasting observational learning of cognitions and behaviors (i.e., imitation of behaviors), and 2) activation and desensitization of emotional processes.

Observational learning. According to widely accepted social cognitive models, a person's social behavior is controlled to a great extent by the interplay of the current situation with individuals' emotional states, their schemas about the world, their normative beliefs about what is appropriate, and the scripts for social behavior that they have learned [11]. During early, middle, and late childhood, children encode in memory social scripts to guide behavior though observation of family, peers, community, and mass media. Consequently observed behaviors are imitated long after they are observed [10]. During this period, children's social cognitive schemas about the world around them also are elaborated. For example extensive observation of violence has been shown to bias children's world schemas toward attributing hostility to others' actions. Such attributions in turn increase the likelihood of children behaving aggressively [12]. As children mature further, normative beliefs about what social behaviors are appropriate become crystallized and begin to act as filters to limit inappropriate social behaviors [13]. These normative beliefs are influenced in part by children's observation of the behaviors of those around them including those observed in the mass media.

Desensitization. Long-term socialization effects of the mass media are also quite likely increased by the way the mass media and video games affect emotions. Repeated expo- sures to emotionally activating media or video games can lead to habituation of certain natural emotional reactions. This process is called "desensitization." Negative emotions experienced automatically by viewers in response to a particular violent or gory scene decline in intensity after many exposures [4]. For example, increased heart rates, perspiration, and self-reports of discomfort often accompany exposure to blood and gore. However, with repeated exposures, this negative emotional response habituates, and the child becomes "desensitized." The child can then think about and plan proactive aggressive acts without experiencing negative affect [4].

Enactive learning. One more theoretical point is important. Observational learning and desensitization do not occur independently of other learning processes. Children are constantly being conditioned and reinforced to behave in certain ways, and this learning may occur during media interactions. For example, because players of violent video games are not just observers but also "active" participants in violent actions and are generally reinforced for using violence to gain desired goals, the effects on stimulating longterm increases in violent behavior should be even greater for video games than for TV, movies, or Internet displays of violence. At the same time, because some video games are played together by social groups (e.g., multiperson games) and because individual games may often be played together by peers, more complex social conditioning processes may be involved that has not yet been empirically examined. These effects, including effects of selection and involvement, need to be explored.

\section{Key Empirical Studies}

Given this theoretical back ground, let us now examine the empirical research that indicates that childhood exposure to media violence has both short- and long-term effects in stimulating aggression and violence in the viewer. Most of this research is on TV, movies, and video games, but from the theory above one can see that the same effects should occur for violence portrayed on various Internet sites (e.g., multiperson game sites, video posting sites, chat rooms) and on handheld cell phones or computers.

\section{Violence in Television, Films, and Video Games}

The fact that most research on the impact of media violence on aggressive behavior has focused on violence in fictional television and film and video games is not surprising, given the prominence of violent content in these media along with the prominence of these media in children's lives.

Children in the United States spend an average of between 3 and 4 hours per day viewing television [14]. The best studies have shown that more than $60 \%$ of programs 
contain some violence, and about $40 \%$ of those contain heavy violence [15]. Children are also spending an increasingly large amount of time playing video games, most of which contain violence. Video game units are now present in $83 \%$ of homes with children [16]. In 2004, children spent 49 minutes per day playing video games, and on any given day, $52 \%$ of children aged $8-18$ years play video games [16]. Video game use peaks during middle childhood, with an average of 65 minutes per day for 8-10-year-olds, and declines to 33 minutes per day for 15-18-year-olds [16]. Most of these games are violent: $94 \%$ of games rated (by the video game industry) as appropriate for teens are described as containing violence, and ratings by independent researchers suggest that the real percentage may be even higher [17]. No published study has quantified the violence in games rated ' $\mathrm{M}$ ' for mature; presumably these are even more likely to be violent.

Meta-analyses that average the effects observed in many studies provide the best overall estimates of the effects of media violence. Two particularly notable meta-analyses are those of Paik and Comstock [18] and Anderson and Bushman [19]. The Paik and Comstock meta-analysis focused on violent TV and films, whereas the Anderson and Bushman meta-analysis focused on violent video games.

Paik and Comstock [18] examined effect sizes from 217 studies published between 1957 and 1990. For the randomized experiments that they reviewed, these investigators found an average effect size ( $r=.38, N=432$ independent tests of hypotheses) that was moderate to large compared with other public health effects. When the analysis was limited to experiments on physical violence against a person, the average $r$ value was still $.32(N=71$ independent tests). This meta-analysis also examined cross-sectional and longitudinal field surveys published between 1957 and 1990. For these studies the authors found an average $r$ value of $.19(N=410$ independent tests $)$. When only those studies were used for which the dependent measure was actual physical aggression against another person $(N=200)$, the effect size remained unchanged. Finally the average correlation of media violence exposure with engaging in criminal violence was .13.

Anderson and Bushman [19] conducted the key metaanalyses on the effects of violent video games. Their metaanalyses revealed effect sizes for violent video games ranging from .15-.30. Specifically, playing violent video games was related to increases in aggressive behavior $(r=.27)$, aggressive affect $(r=.19)$, aggressive cognitions (i.e., aggressive thoughts, beliefs, and attitudes; $r=.27$ ), and physiological arousal $(r=.22)$ and was related to decreases in prosocial (helping) behavior $(r=-.27)$. Furthermore, when studies were coded for the quality of their methodology, the best studies yielded larger effect sizes than the "not-best" studies.

One criticism sometimes leveled at meta-analyses is based on the "file drawer effect." This refers to the fact that studies with "nonsignificant" results are less likely to be published and to appear in meta-analyses. However one can correct for this problem by estimating how many "nulleffect" studies it would take to change the results of the meta-analysis. This has been done with the above metaanalyses, and the numbers are very large. For example, Paik and Comstock [18] show that more than 500,000 cases of null effects would have to exist in file drawers to change their overall conclusion of a significant positive relation between exposure to media violence and aggression.

Although meta-analyses are good for obtaining a summary view of what the research shows, a better understanding of the research can be obtained by examining a few key specific studies in more detail.

Experiments. Generally experiments have demonstrated that exposing people, especially children and youth, to violent behavior on film and TV increases the likelihood that they will behave aggressively immediately afterward. In the typical paradigm, randomly selected individuals are shown either a violent or nonviolent short film or TV program or asked to play a violent or nonviolent video game, and are then observed as they have the opportunity to aggress. For children this generally means playing with other children in situations that might stimulate conflict; for adults it generally means participating in a competitive activity in which winning seems to involve inflicting pain on another person.

Children in such experiments who see the violent film clip or play the violent game typically behave more aggressively immediately afterward than those who view or play the nonviolent ones [20-22]. For example Josephson [22] randomly assigned 396 boys, 7-9 years old, to watch either a violent or a nonviolent film before they played a game of floor hockey in school. Observers who did not know what movie any boy had seen recorded the number of times each boy physically attacked another boy during the game. Physical attack was defined to include hitting, elbowing, or shoving another player to the floor, as well as tripping, kneeing, and other assaultive behaviors that would be penalized in hockey. For some children the referees carried a walkie-talkie, a specific cue that had appeared in the violent film that was expected to remind the boys of the movie they had seen earlier. For boys rated by their teacher as frequently aggressive, the combination of seeing a violent film and seeing the movie-associated cue stimulated significantly more assaultive behavior than any other combination of film and cue. Parallel results have been found in randomized experiments for preschoolers who physically attack each other more often after watching violent videos [21] and for older delinquent adolescents who get into more fights on days that they see more violent films [23].

In a randomized experiment with violent video games, Irwin and Gross [24] assessed physical aggression (e.g., hitting, shoving, pinching, kicking) between boys who had 
just played either a violent or a nonviolent video game. Those who had played the violent video game were more physically aggressive toward peers. Other randomized experiments have measured college students' propensity to be physically aggressive after they had played (or not played) a violent video game. For example Bartholow and Anderson [25] found that male and female college students who had played a violent game subsequently delivered more than two and a half times as many high-intensity punishments to a peer as those who played a nonviolent video game. Other experiments have shown that it is the violence in video games, not the excitement that playing them provokes, that produces the increase in aggression [26].

In summary, experiments unambiguously show that viewing violent videos, films, cartoons, or TV dramas or playing violent video games "cause" the risk to go up that the observing child will behave seriously aggressively toward others immediately afterward. This is true of preschoolers, elementary school children, high school children, college students, and adults. Those who watch the violent clips tend to behave more aggressively than those who view nonviolent clips, and they adopt beliefs that are more accepting of violence [27].

One more quasi-experiment frequently cited by game manufacturers should be mentioned here. Williams and Skoric [28] have published the results of a dissertation study of cooperative online game playing by adults in which they report no significant long-term effects of playing a violent game on the adult's behavior. However the low statistical power of the study, the numerous methodological flaws (self-selection of a biased sample, lack of an adequate control group, the lack of adequate behavioral measures) make the validity of the study highly questionable. Furthermore the participants were adults, for whom there would be little theoretical reason to expect long-term effects.

Cross-sectional and longitudinal studies. Empirical crosssectional and longitudinal studies of youth behaving and watching or playing violent media in their natural environments do not test causation as well as experiments do, but they provide strong evidence that the causal processes demonstrated in experiments generalize to violence observed in the real world and have significant effects on real-world violent behavior. As reported in the discussion of metaanalyses above, the great majority of competently done one-shot survey studies have shown that children who watch more media violence day in and day out behave more aggressively day in and day out [18]. The relationship is less strong than that observed in laboratory experiments, but it is nonetheless large enough to be socially significant; the correlations obtained are usually are between .15 and .30 . Moreover the relation is highly replicable, even across researchers who disagree about the reasons for the relationship [29], and across countries $[30,31]$.
Complementing these one-time survey studies are the longitudinal real-world studies that have shown correlations over time from childhood viewing of media violence to later adolescent and adult aggressive behavior [31-35] (for reviews see $[4,27,33])$. These studies have shown that early habitual exposure to media violence in middle-childhood predicts increased aggressiveness 1 year, 3 years, 10 years, 15 years, and 22 years later in adulthood, even controlling for early aggressiveness. On the other hand, behaving aggressively in childhood is a much weaker predictor of higher subsequent viewing of violence when initial violence viewing is controlled, making it implausible that the correlation between aggression and violent media use was primarily due to aggressive children turning to watching more violence [31-33]. As discussed below, the pattern of results suggests that the strongest contribution to the correlation is the stimulation of aggression from exposure to media violence, but that those behaving aggressively may also have a tendency to turn to watching more violence, leading to a downward spiral effect [35].

One example is illustrative. In a study of children interviewed each year for 3 years as they moved through middle childhood, Huesmann et al [30,31] found increasing rates of aggression for both boys and girls who watched more television violence, even with controls for initial aggressiveness and many other background factors. Children who identified with the portrayed aggressor and those who perceived the violence as realistic were especially likely to show these observational learning effects. A 15-year follow-up of these children [33] demonstrated that those who habitually watched more TV violence in their middle-childhood years grew up to be more aggressive young adults. For example, among children who were in the upper quartile on violence viewing in middle childhood, $11 \%$ of the males had been convicted of a crime (compared with 3\% for other males), $42 \%$ had "pushed, grabbed, or shoved their spouse" in the past year (compared with 22\% of other males), and 69\% had "shoved a person" when made angry in the past year (compared with $50 \%$ of other males). For females, 39\% of the high-violence viewers had "thrown something at their spouse" in the past year (compared with $17 \%$ of the other females), and $17 \%$ had "punched, beaten, or choked" another adult when angry in the past year (compared with $4 \%$ of the other females). These effects were not attributable to any of a large set of child and parent characteristics including demographic factors, intelligence, and parenting practices. Overall for both males and females the effect of middle-childhood violence viewing on young adult aggression was significant even when controlling for their initial aggression. In contrast the effect of middle-childhood aggression on adult violence viewing when controlling for initial violence viewing was nonsignificant, although it was positive. 


\section{Moderators of Media Violence Effects}

Obviously not all observers of violence are affected equally by what they observe at all times. Research has shown that the effects of media violence on children are moderated by situational characteristics of the presentation, including how well it attracts and sustains attention, personal characteristics of the viewer including their aggressive predispositions, and characteristics of the physical and human context in which the children are exposed to violence.

In terms of plot characteristics, portraying violence as justified and showing rewards (or at least not showing punishments) for violence increase the effects that media violence has in stimulating aggression, particularly in the long run $[27,36,37]$. As for viewer characteristics that depend on perceptions of the plot, those viewers who perceive the violence as telling about life more like it really is and who identify more with the perpetrator of the violence are also stimulated more toward violent behavior in the long run $[27,30,33,38]$. Taken together these facts mean that violent acts by charismatic heroes that appear justified and are rewarded are the violent acts most likely to increase viewers' aggression.

A number of researchers have suggested that, independently of the plot, viewers or game players who are already aggressive should be the only ones affected. This is certainly not true. Although the already aggressive child who watches or plays a lot of violent media may become the most aggressive young adult, the research shows that even initially unaggressive children are made more aggressive by viewing media violence $[27,32,33]$. Long-term effects do appear to be stronger for younger children [3,14], but shortterm affects appear, if anything, stronger for older children [3], perhaps because one needs to have already learned aggressive scripts to have them primed by violent displays. Although the effects appeared weaker for females 40 years ago [32], they appear equally strong today [33]. Finally having a high IQ does not seem to protect a child against being influenced [27].

\section{Mediators of Media Violence Effects}

Most researchers believe that the long-term effects of media violence depend on social cognitions that control social behavior being changed for the long run. More research needs to completed to identify all the mediators, but it seems clear that they include normative beliefs about what kinds of social behaviors are acceptable $[4,13,27]$, world schemas that lead to hostile or nonhostile attributions about others' intentions $[4,12,27]$, and social scripts that automatically control social behavior once they are well learned $[4,11,27]$.

\section{Summary}

This review marshals evidence that compelling points to the conclusion that media violence increases the risk significantly that the viewer or game player will behave more violently both in the short and long run. Randomized experiments demonstrate conclusively that exposure to media violence immediately increases the likelihood of aggressive behavior for both children and adults in the short run. The most important underlying process for this effect is probably priming, although mimicry and increased arousal also play important roles. The evidence from longitudinal field studies is also compelling that children's exposure to violent electronic media including violent games leads to long-term increases in their risk for behaving aggressively and violently. These long-term effects are a consequence of the powerful observational learning and desensitization processes that neuroscientists and psychologists now understand to occur automatically in the human child. Children automatically acquire scripts for the behaviors they observe around them in real life or in the media, along with emotional reactions and social cognitions that support those behaviors. Social comparison processes also lead children to seek out others who behave in similar aggressive manners in the media or in real life, leading to a downward spiral process [35] that increases risk for violent behavior.

One valid remaining question is whether the size of this effect is large enough that one should consider it to be a public health threat. The answer seems to be yes. Two calculations support this conclusion. First, according to the best meta-analyses $[18,19]$ the long-term size of the effect of exposure to media violence in childhood on later aggressive or violent behavior is about equivalent to a correlation of .20-.30. Although some might argue that this explains only $4-9 \%$ of the individual variation in aggressive behavior, as several scholars have pointed out $[39,40]$, percent variance explained is not a good statistic to use when predicting low-probability events with high social costs. For example, a correlation of .3 with aggression translates into a change in the odds of aggression from 50/50 to 65/35- not a trivial change when one is dealing with life-threatening behavior [40].

Second, the effect size of media violence is the same or larger than the effect size of many other recognized threats to public health. In Figure 1 in the Bushman and Huesmann report [41], the effect sizes for many common threats to public health are compared with the effect that media violence has on aggression. The only effect slightly larger than the effect of media violence on aggression is that of cigarette smoking on lung cancer.

In summary, exposure to electronic media violence increases the risk of both children and adults behaving aggressively in the short-run and of children behaving aggressively in the long-run. It increases the risk significantly, and it increases it as much as many other factors that are con- 


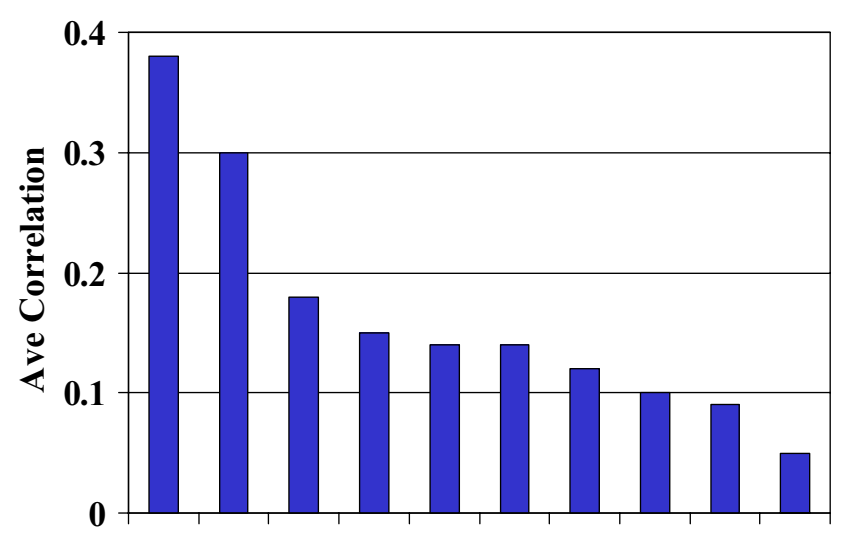

$\begin{array}{llllllllll}\text { A } & \text { B } & \text { C } & \text { D } & \text { E } & \text { F } & \text { G } & \text { H } & \text { I } & \text { J }\end{array}$
A. Smoking and lung cancer
B. Media violence and aggression
C. Condom use and sexually transmitted HIV
D. Passive smoking and lung cancer at work
E. Exposure to lead and IQ scores in children
F. Nicotine patch and smoking cessation
G. Calcium intake and bone mass
H. Homework and academic achievement
I. Exposure to asbestos and laryngeal cancer
J. Self-examination and extent of breast cancer

Figure 1. The relative strength of known public health threats.

sidered public health threats. As with many other public health threats, not every child who is exposed to this threat will acquire the affliction of violent behavior, and many will acquire the affliction who are not exposed to the threat. However that does not diminish the need to address the threat.

\section{References}

[1] Moffitt TE, Caspi A, Harrington H, Milne BJ. Males on the lifecourse-persistent and adolescence-limited antisocial pathways: Follow-up at age 26 years. Dev Psychopathol 2002;14:179-207.

[2] Huesmann LR, Eron LD, Lefkowitz MM, Walder LO. The stability of aggression over time and generations. Dev Psych 1984;20:1120-34.

[3] Bushman BJ, Huesmann LR. Short-term and long-term effects of violent media on aggression in children and adults. Arch Pediatr Adolesc Med 2006;160:348-52.

[4] Huesmann LR, Kirwil L. Why observing violence increases the risk of violent behavior in the observer. In Flannery D, ed. The Cambridge Handbook of Violent Behavior and Aggression. Cambridge, United Kingdom, Cambridge University Press; 2007.

[5] Berkowitz L, LePage A. Weapons as aggression-eliciting stimuli. J Pers Soc Psychol 1967;7:202-7.

[6] Bryant J, Zillmann D. Effect of intensification of annoyance through unrelated residual excitation on substantially delayed hostile behavior. J Exp Soc Psychol 1979;15:470-80.

[7] Geen RG, O'Neal EC. Activation of cue-elicited aggression by general arousal. J Pers Soc Psychol 1969;11:289-92.

[8] Huesmann LR. Imitation and the effects of observing media violence on behavior. In: S. Hurley S, Chater N, eds. Perspectives on Imitation:
From Neuroscience to Social Science; Volume 2: Imitation, Human Development, and Culture. Cambridge, Massachusetts, MIT Press, 2005.

[9] Meltzoff AN, Moore MK. Imitation of facial and manual gestures by human neonates: Resolving the debate about early imitation. In: Muir D, Slater A, eds. Infant Development: The Essential Readings. Malden, Massachusetts, Blackwell Publishers, 2000.

[10] Rizzolati G, Fadiga L, Gallese V, Fogassi L. Premotor cortex and the recognition of motor actions. Cognitive Brain Res 1996;3:131-41.

[11] Huesmann LR. The role of social information processing and cognitive schema in the acquisition and maintenance of habitual aggressive behavior. In: Geen RG, Donnerstein E, eds. Human Aggression: Theories, Research, and Implications for Social Policy. New York, New York, Academic Press, 1998.

[12] Dodge KA. Attributional bias in aggressive children. In: Kendall PC, ed. Advances in Cognitive-Behavioral Research and Therapy. San Diego, California, Academic Press, 1985.

[13] Huesmann LR, Guerra NG. Children's normative beliefs about aggression and aggressive behavior. J Pers Soc Psychol 1997;72: 408-19.

[14] Comstock G, Paik H. Television and the American Child. San Diego, California, Academic Press, 1991.

[15] Wilson BJ, Kunkel D, Linz D, et al. Violence in television programming overall: University of California, Santa Barbara study. In: Seawall M, ed. National Television Violence Study. Thousand Oaks, California, Sage Publications, 1997.

[16] Roberts DF, Foehr UG, Rideout VJ. Generation M: Media in the lives of 8-18 year-olds. Menlo Park, California, Henry J. Kaiser Family Foundation, 2005.

[17] Haninger K, Thompson KM. Content and ratings of teen-rated video games. JAMA 2004;291:856-65.

[18] Paik H, Comstock G. The effects of television violence on antisocial behavior: A meta-analysis. Commun Res 1994;21:516-46.

[19] Anderson CA, Bushman BJ. Effects of violent video games on aggressive behavior, aggressive cognition, aggressive affect, physiological arousal, and prosocial behavior: A meta-analytic review of the scientific literature. Psychol Sci 2001;12:353-9.

[20] Bandura A, Ross D, Ross SA. Imitation of film-mediated aggressive models. J Abnorm Soc Psychol 1963;67:3-11.

[21] Bjorkqvist K. Violent Films, Anxiety, and Aggression. Helsinki, Finland, Finnish Society of Sciences and Letters, 1985.

[22] Josephson WL. Television violence and children's aggression: Testing the priming, social script, and disinhibition predictions. J Pers Soc Psychol 1987;53:882-90.

[23] Leyens JP, Parke RD, Camino L, Berkowitz L. Effects of movie violence on aggression in a field setting as a function of group dominance and cohesion. J Pers Soc Psychol 1975;32:346-60.

[24] Irwin AR, Gross AM. Cognitive tempo, violent video games, and aggressive behavior in young boys. J Fam Violence 1995;10:337-50.

[25] Bartholow BD, Anderson CA. Effects of violent video games on aggressive behavior: Potential sex differences. J Exp Soc Psychol 2002;38:283-90.

[26] Anderson CA. Effects of violent movies and trait irritability on hostile feelings and aggressive thoughts. Aggressive Behav 1997;23:161-78.

[27] Anderson CA, Berkowitz L, Donnerstein E, et al. The influence of media violence on youth. Psychol Sci Public Interest 2003;4:81-110.

[28] Williams D, Skoric M. Internet fantasy violence: A test of aggression in an online game. Commun Monogr 2005;72:217-33.

[29] Milavsky JR. Television and Aggression: A Panel Study. Quantitative Studies in Social Relations. New York, New York, Academic Press; 1982.

[30] Huesmann LR, Lagerspetz K, Eron LD. Intervening variables in the TV violence-aggression relation: Evidence from two countries. Dev Psych 1984;20:746-75. 
[31] Huesmann LR, Eron LD, eds. Television and the Aggressive Child: A Cross-National Comparison. Hillsdale, New Jersey, Erlbaum, 1986.

[32] Eron LD, Huesmann LR, Lefkowitz MM, Walder LO. Does television violence cause aggression? Am Psychol 1972;27:253-63.

[33] Huesmann LR, Moise-Titus J, Podolski CL, Eron LD. Longitudinal relations between children's exposure to TV violence and their aggressive and violent behavior in young adulthood: 1977-1992. Dev Psychol 2003;39:201-21.

[34] Huesmann LR, Miller LS. Long-term effects of repeated exposure to media violence in childhood. In: Huesmann LR, ed. Aggressive Behavior: Current Perspectives. New York, New York, Plenum Press, 1994.

[35] Slater MD, Henry KL, Swaim RC, Anderson LL. Violent media content and aggressiveness in adolescents: A downward spiral model. Commun Res 2003;30:713-36.
[36] Bandura A, Ross D, Ross SA. Vicarious reinforcement and imitative learning. J Abnorm Soc Psychol 1963;67:601-7.

[37] Berkowitz L, Powers PC. Effects of timing and justification of witnessed aggression on the observers' punitiveness. J Res Pers 1979; 13:71-80.

[38] Leyens JP, Picus S. Identification with the winner of a fight and name mediation: Their differential effects upon subsequent aggressive behavior. Br J Soc Clin Psychol 1973;12:374-7.

[39] Abelson RP. 1985. A variance explanation paradox: When a little is a lot. Psychol Bull 1985;97:129-33.

[40] Rosenthal R. Media violence, antisocial behavior, and the social consequences of small effects. J Soc Issues 1986;42:141-54.

[41] Bushman BJ, Huesmann LR. Effects of televised violence on aggression. In: Singer J, ed. Handbook of Children and the Media. Thousand Oaks, California, Sage Publications, 2001. 